NASA Technical Memorandum 101493

\title{
RAREFIED FLOW PAST A FLAT PLATE
}

AT INCIDENCE

(BASA-TH-101493) RAREEIED FLCV EAST A RLAT

EIATE AT INCIDERC (AASA) IIP CSCL 2OD
N $89-13759$

Declas

$63 / 34 \quad 0183275$

Virendra K. Dogra

James N. Moss

Joseph M. Price

September 1988

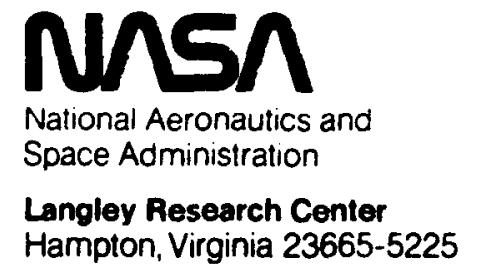




\title{
RAREFIED FLOW PAST A FLAT PLATE AT INCIDENCE
}

\author{
V. K. Dogra \\ Vigyan Research Associates, Inc. \\ Hampton, Virginia 23666 \\ James N. Moss and Joseph M. Price \\ NASA Langley Research Center \\ Hampton, Virginia 23665
}

\begin{abstract}
Results of a numerical study using the direct simulation Monte Carlo (DSMC) method are presented for the transitional flow about a flat plate at 40 degree incldence. The plate has zero thickness and a length of $1.0 \mathrm{~m}$. The flow conditions simulated are those experienced by the Shuttle Orbiter during reentry at $7.5 \mathrm{~km} / \mathrm{s}$. The range of freestream conditions are such that the freestream Knudsen number valies are between 0.02 and 8.4 , that is, conditions that encompass most of the transitional flow regime. The DSMC simulations show that transitional effects are evident when compared with free molecule results for all cases considered. The calculated results demonstrate clearly the necessity of having a means of identifying the effects of transitional flow when making aerodynamic flight measurements as are currently being made with the Space Shuttle Orbiter vehicles. Previous flight data analyses have relied exclusively on adjustments in the gassurface interaction nodels without accounting for the transitional effect which can be comparable in magnitude. The present calculations show that the transitional effect at $175 \mathrm{~km}$ would increase the Space Shuttle Orbiter lift-drag ratio by 90 percent over the free molecular value.
\end{abstract}




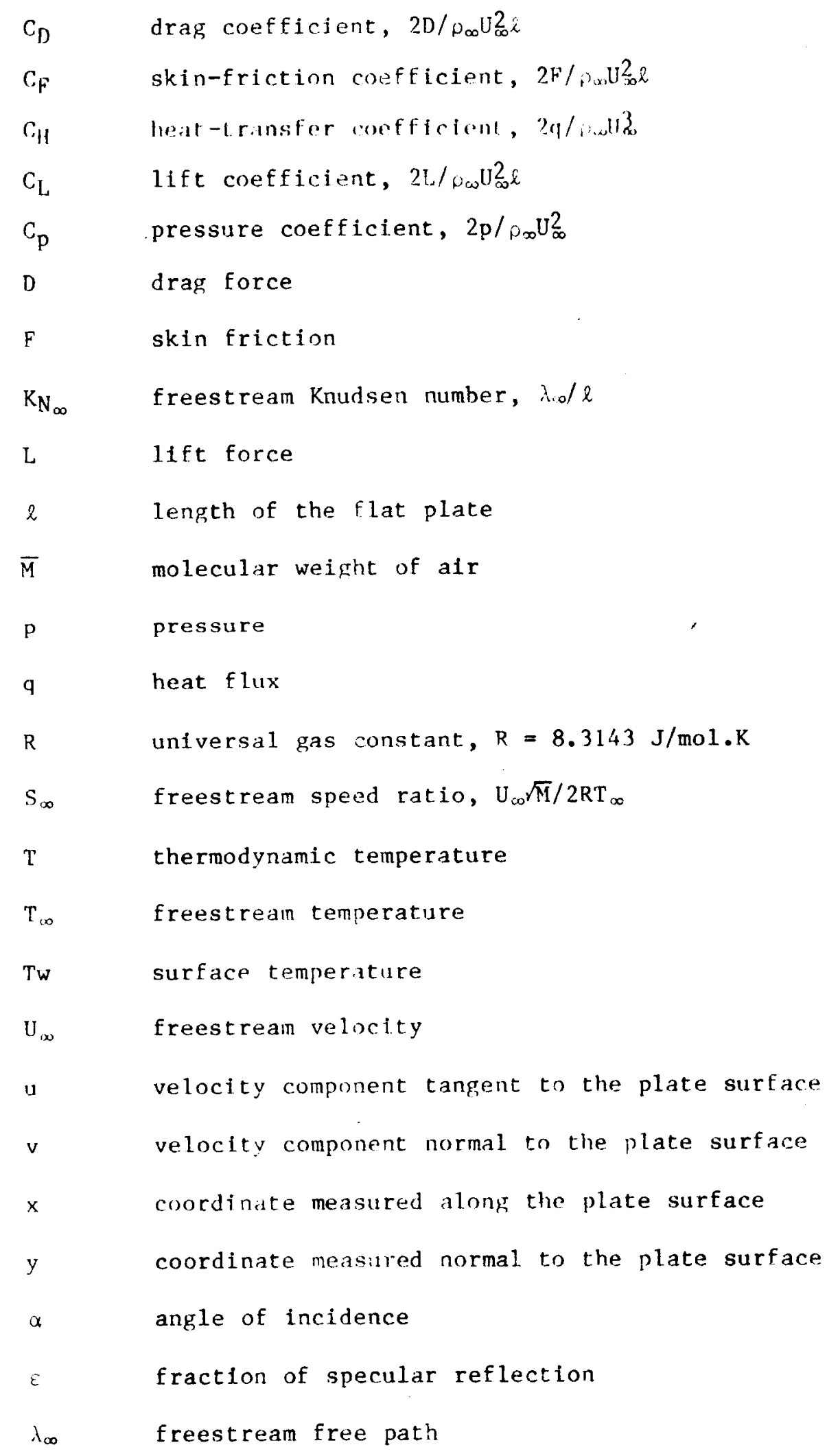




$\begin{array}{ll}\rho_{\infty} & \text { freestream density } \\ \rho & \text { density }\end{array}$

ORIGINAL PAGE IS

OP POOR QUALITY

\section{Introduction}

The development and application of future hypersonis spacr vehicles require accurate predictions of aerothermal loads diring reentry. A portion of the reentry for these vehicles will take place in the transirional flow regime where nonequilibrium effects become important in establishing the thermal and aerodynamic response of these vehicles. In order to simplify the computational requirements, the lift-drag characteristics for vehicles such as the space Shuttle orbiter are often approximated ${ }^{1.2}$ with a flat plate at incidence for the free molecular regime. For the transitional flow regine, empirical approximations are norinally used to predict the aerodynamic forces for such vehicles. Examples of such applications are given 1n Refs. 1, 2, and 3 for the Space Shuttle Orbiter. Therefore, numerical studies on basic configurations such as a plate at incidence can provide useful information and physical insight concerning the nature of transitional flows.

A flat plate as a baslc aerodynanic surface has remained the focus of the transitional flow research by several authors [Refs. 4-8]. But most of these investigations are for zero incidence and do not cover the range of flow parameters of interest. There are very few experimental and theoretical Investigations of the flat plate at incidence [Refs. 9 and 10]. Fven these do not cover the large jncidence and high speed ratio chacacteristics of hypersonic flight. Furthermore, they are $11 \mathrm{mited}$ to the continuum flow regime.

In the present paper the direct simulation Monte Carlo (DSMC) method of Bird, ${ }^{0-11}$ with the variable hard sphere (VHS) molecular model, is nsed to 
simulate the transitional flow past a flat plate at in degree incidence. The flow conditions and incidence angle simulated are those which the Space Shuttle Orbiter experiences during reentry. The DSMC is the only suitable numerical technique to simulate the transitional flow regine accurately because it allows the direct implementation of nonequilibrium flow models. The various nonequilibrium phenomena are the main characteristics of the transitional flow regime, and the DSMC method simulates the flow physics adequately. The present calculations show that the transitional effect for a diffuse surface would increase the Space Shuttle lift-drag rat lo by 90 percent over the free molecular value at approximately $175 \mathrm{~km}$ alt itude.

\section{Computational Approach}

The DSMC method ${ }^{11-12}$ models the real gas by sone thousands of simulated molecules in a computer. The position condinates, velocity components, and internal state of each molecule are stored in the computer and are modified with time as the molecules are concurrently followed through representative collistons and boundary interactions in simulated physical space. The time parameter in the simulation may be identffled with physical time in the real flow, and all calculations are unsteady. When the boundary contitions are such that the flow is steady, then the solution is the asymptotic limit of unsteady flow. The computation is always started from an initial state that permits an exact specification such as a vacuum or uniform equilibrium flow. Consequently, the method does not require an initial approximation to the flowfield and does not involve any iterative procedires. A computational cell network is required in physical space only, and then only to facilitate the choice of potential collision pairs and the sampling of the macroscopic flow properties. Furtherinore, advantage may be taken of flow 
symmetries to reduce the dimensions of the cell network and the number of position coordinates that need to be stored for each molecule, but the collisions are always treated as three-dinenstonal phenomenis. The boundary condtions are specified in terms of the behavior of the individial molecules rather than the distribution functions. All procedures may be spectfied in such a manner that the computational time is directly proportional to the number of simulated molecules.

\section{Conditions for Calculations}

The freestream conditions considered in the present study are for an altitude range of 90 to $130 \mathrm{~km}$. For the $1.0-\mathrm{m}$ flat plate with zero thickness, the corresponding freestream Knudsen numbers are 0.023 to 8.439 . During the Shuttle's reentry trajectory, the same freestream Knudsen numbers based on the mean aecodynamic chord of $12 \mathrm{~m}$ correspond approximately to an altitude range of 100 to $175 \mathrm{~km}$. The freestream velocity, incidence angle, and wall temperature are assumed constant at $7.5 \mathrm{~km} / \mathrm{s}, 40 \mathrm{deg}$, and $1000 \mathrm{~K}$, respectively, that is, conditions experlenced by the Space shuttle orbiter during reentry. These conditions are summarized in Table 1 , where the freestream values are those given by Jacchia ${ }^{13}$ for an exospheric temperature of $1200 \mathrm{~K}$.

The surface of the plate is assumed to be diffused with full thermal accommodation and to promote recombination of the oxygen and nitrogen atoms. Recombination probabilities appropriate for the Shuttle thermal protection tiles are imposed. The oxygen and nitrogen recombination probabilttles are 0.0049 and 0.0077 , respectively.

Since the computational requirements increase significantly with increasing freestream density, computations are performed only in the transitional flow regime. 


\section{Results and Discussion}

Since the flat plate at incidence is a basic element of lifting surfaces, it is often used for numertcal and experimental studies in hypersonic flow research. Furthermore, the conflguration is also helpful in understanding the reentry of space vehicles such as the Space Shuttle Orbiter. Therefore, attention is focused on the flow structure, surface quantities, and aerodynanic characteristics resulting from low-density flow about a flat plate at 40 degree angle of attack (Fig. 1).

\section{Flowfield Structure}

Figures 2 to 7 present calculated flowfield quantities on the compression side (lower sirface) of a flat plate at two freestream Knudsen numbers $(0.023$ and 8.439$)$. Results at three different locations along the surface are presented. Two regions of interest are those near the plate surface and the shock wave. Near the surface, a large increase in density occurs which is characteristic of a high-velocity flow about a cold wall. These results also clearly demonstrate that the shock wave is fully merged with the viscous layer for Knudsen number values of 0.023 and 8.439 . The density and velocity profiles for a Knudsen number value of 0.023 (Figs. 2 and 3) show that the shock wave thickness increases gradually along the surface of the plate. However, for a freestream knudsen number of 8.439 (F1gs. 5 and 6), the extent of the flowfield disturbances remains almost constant along the surface because of the large degree of rarefaction at this Knudsen number.

The overall nondimensional. kinetic temperature, $\mathrm{T} / \mathrm{T}_{\infty}$, shown in Figs. 4 and 7 for the freestream Knudsen number values of 0.023 and 8.439 , respectively, is defined for a nonequilibrium gas as the weighted mean of 
the translational and interual temperatures. These figures show that the overall kinetic temperature rise in the shock wave precedes the density rise. The initial rise in temperature is due to the bimodal velocity distribution: the molecular sample consists of mostly undisturbed freestream molecules with just a few molecules that have been affected by the shock. The large velocity separation between these two classes of molecules results in the early temperature increase.

The temperature rise in the shock wave is comparatively large near the leading edge and then gradually decreases toward the trailing edge (Figs. 4 and 7). This obviously shows that the strength of the shock wave decreases along the surface of the flat plate. The difference in peak shock-wave temperatures at different locations is less for the higher Knudsen number condition. The shock wave is very diffuse for the higher Knudsen number condition hecause of the large freestream mean free path. The temperature and velocity profiles also show a significant temperature jump and velocity slip at the surface for both values of Knudsen number. Consequently, the flowfield exhibits the effects of rarefaction for all the cases considered.

\section{Surface Quantities}

The surface pressure, skin friction, and heat transfer coefficlents are presented in Figs. 8, 9, and 10, respectively, for the lower surface of the flat plate at 40 -deg incidence. The effects of rarefaction are shown by comparing the results for different freestream Knudsen numbers. The variation of the pressure coefficient with rarefaction is moderate provided the gas-surface interaction is diffuse, as assumed in the present calculations. The calculated pressure coefficient is greater than the free molecular value for large freestream Knudsen numbers. In contrast, the sin friction and 
heat transfer coefficients (Figs. 9 and 10 ) are very sensitive to rarefaction effects and approach the free molecule value with lucreasing rarefaction.

\section{Aerodynamic Characteristics}

Figures 11 and 12 present the drag and lift coefficients as a function of Ereestream Knudsen number for the flat plate at 40-deg incidence. These results show the expected variation in the transitional flow regime. The drag coefficient increases and the lift coefficient decreases substantially with increasing ratefaction, and both approach the free molecule limit. The change in the dray and lift coefficients is due primarily to an increase in the skin friction rather than to a change in the pressure coefficient. Figure 13 presents the the lift-drag ratio as a function of freestream Knudsen number where the trend is the same as the lift coefficient data, which experience a significant decrease with increasing rarefaction.

The effect of angle of incidence varlation on the aerodynainic coefficients is demonstrated in Figs. 14 to 16 for the $8 .+$ Knudsen number case. The DSMC results are compared with those obtained using free molecule expressions for lift and drag coefficients and lift-drag ratio. Figure 14 shows that the lift coefficient increases with angle of attack, reaches a maximum value at 45 deg, then decreases with further increase in angle of attack. The DSMC values are considerably higher than the free molecule values, indicating that transitional effects are evident even at this highly rarefled condition. Figure 15 shows that the drag coefficient agrees well with the free molecule calculations for small incidence. However, at higher incldence the DSMC values are slightly lower than free molecule values because of the over prediction of skin friction by the free molecule 
method. Figure 16 presents the corresponding lift-drag ratio comparison and shows the same trend of the transitional effects as in the lift coefficient data.

These results have important implications for the interpretation of flight measurements used to deduce aerodynanic coefficients under rarefled conditions. As early as 1985, it was recognized (Ref. 14) that transttional effects rather than specular reflection might be influencing the interpretation of the flight measurements; however, no calculations were available to establish the fact. At altitudes of $160 \mathrm{~km}$ and above, the conventional procedure ${ }^{i-3}$ has been to interpret the flight measurements using the free molecule flow calculations. Such procedures are used to establish what fraction of the gas-sicface interaction is specular. But it can be seen from the present calculations that the transitional effects persist even at very high altitudes ( $160 \mathrm{~km}$ and above). This is clearly demonstrated in Pig. 16 where the transitional effect increases the lift-drag ratio by 90 percent for a flat plate at 40-deg incidence. The Ereestream Knudsen number for this condition 1 s 8.4 which corresponds to Shuttle conditions at approximately $175 \mathrm{~km}$. This transitional effect is quite large, and if not properly interpreted could be mistaken for a contribution due to the specular reflection. For example, the free molecule results for lift-drag ratio as a function of angle of incidence for different fractions of specular reflection are shown in Fig. 17. As the fraction of specular reflection increases, the lift-drag ratio also increases for a given incidence angle. Since these two separate effects both produce increased lift-drag ratio, interpretation of flight measurements must accisunt for the transtional effects. 


\section{Conclusions}

Results obtained with the direct simulation Monte Car1o (DSMC) method for hypersonic flow past a flat plate at incldence show the effects of the transitional flow regime on the aerodynamic characteristics. These effects are significant even for large freestream Knudsen numbers. Thus, the Interpretation of aerodynamic flight data for space vehicles such as the Space Shuttle Orbiter must be done in concert with calculations that describe the transitional effects. Fallure to account for this effect could significantly distort the interpretation of the gas-surface interactions under highly rarefled conditions.

\section{References}

${ }^{l}$ Blanchard, R. C., "Rarefled Flow Lift-to-Drag Measurements of the Shuttle Orbiter," 15th Congress of International Counc1l of Aeronautical Sciences, Paper ICAS-86-2.10.2, London, England, Sept. 7-12, 1986. ${ }^{2}$ Blanchard, R. C., Hendrix, M. K., Fox, J. C., Thomas, D. J., and Nicholson, J. Y., "Orbital Acceleration Research Experiment," Journal of Spacecraft and Rockets, Vol. 24, No. 6, November-December, 1987.

${ }^{3}$ Aerodynamic Design Data Book, Volume 1, Orbiter Vehicle 102, SD72-SH-0060, Volume IM, November 1980, Space Division, Rockwell International.

${ }^{4}$ Vogenitz, F. V., Broadwe11, J. E., and Bird, G. A., "Leading Edge Flow by Monte Carlo Direct Simulation Technique," AIAA Journal, Vol. 8, No. 3, 1971, pp. $304-310$.

5ogenitz, F. V. and Takata, G. Y., "Rarefied Gas Flow about Cones and Flat Plates by Monte Carlo Simulation," AIAA Journal, Vol. 9, No. 1, 1971, pp. 91-100. 
snakhore, F. M., "Rarefied Gas Flow Over a Plate Parallel to the Stream," USSR Fluid Dynamics, 1973 , pp. 119-126.

7Beottcher, R. D., Koppenwallner, G., and Legge, H., "Flat Plate Skin Friction in the Range between Hypersonic Continuum and Free Molecular Flow," Proc. 10th Internatlonal Symposium on Rarefled Gas Bynamics, Aspen, CO, Vol. 1, 1976, pp. 348-359.

${ }^{8}$ Hermina, W. L., Monte Carlo Simulation of Rarefied Flow Along a Flat Plate", AIAA Paper 87-1547, June, 1987.

${ }^{9}$ Al legre, J. and Bisch, C., "Angle of Attack and Leading Fdge FEfects on the Flow about a Flat Plate at Mach Number 18," AIAA Journa1, Vol. 6, No. 5, 1968, pp. $848-852$

${ }^{10}$ Gai, S.L., "An Experimental study of the Flow Past a Flat Plate at Incidence in Supersonie Low Density Stream," Rarefied Gas Dynamics, Univ. Tokyo Press, edited by Oguchi H., Vol. 1, 1984, pp. 257-264.

"Bird, G. A., "Monte Carlo Simulation in an Engineering Context," AIAA Progress in Astronautics and Aeronautics: Rarefied Gas Dynamics, Vo1. 74 , Part 1, edited by Sam S. Fisher, 1981, pp. 235-239.

${ }^{12}$ Bird, G. A., Molecular Gas Dynamics, Clarendon Press, Oxford, 1976.

13.Jacchia, I. C., "Theruospheric Temperature Density, and Composition: New Models," Research In Space Science, SAO Special Report No. 375, March 1977. l'Blanchard, R. C. and Rutherford, J. F., "Shuttle Orbiter High Resolution Accelerometer Package Experiment: Prelininary Flight Results," Journal of Spacecraft and Rockets, Vol. 22, No. 4, July-August, 1985, pp. 474-480. 
Table 1. Freestrean Conditions

[Length of the flat plate, $\ell,=1 \mathrm{~m}$, and angle of incidencr, $\alpha,=40 \mathrm{deg}$. ]

\begin{tabular}{|c|c|c|c|c|c|c|}
\hline $\begin{array}{l}\text { Altitude, } \\
\mathrm{km}\end{array}$ & s/mol & $\mathrm{K}_{N_{\infty}}$ & $\begin{array}{c}\mathrm{J} \mathrm{J}_{\infty}, \\
\mathrm{kn} / \mathrm{sec}\end{array}$ & $\mathrm{kg} / \mathrm{m}^{\mathrm{m}} 3$ & ${ }^{\mathrm{T}} \mathrm{K}_{\mathrm{K}}$ & $S_{\infty}$ \\
\hline 90 & 28.810 & 0.023 & 7.5 & $3.418 \times 10^{-6}$ & 198 & 23.1 \\
\hline 100 & 28.257 & 0.137 & 7.5 & $5.640 \times 10^{-7}$ & 194.3 & 21.6 \\
\hline 120 & 26.159 & 3.146 & 7.5 & $2.269 \times 10^{-8}$ & 367.8 & 15.7 \\
\hline 130 & 25.441 & 8.439 & 7.5 & $8.220 \times 1 n^{-9}$ & 499.7 & 13.3 \\
\hline
\end{tabular}




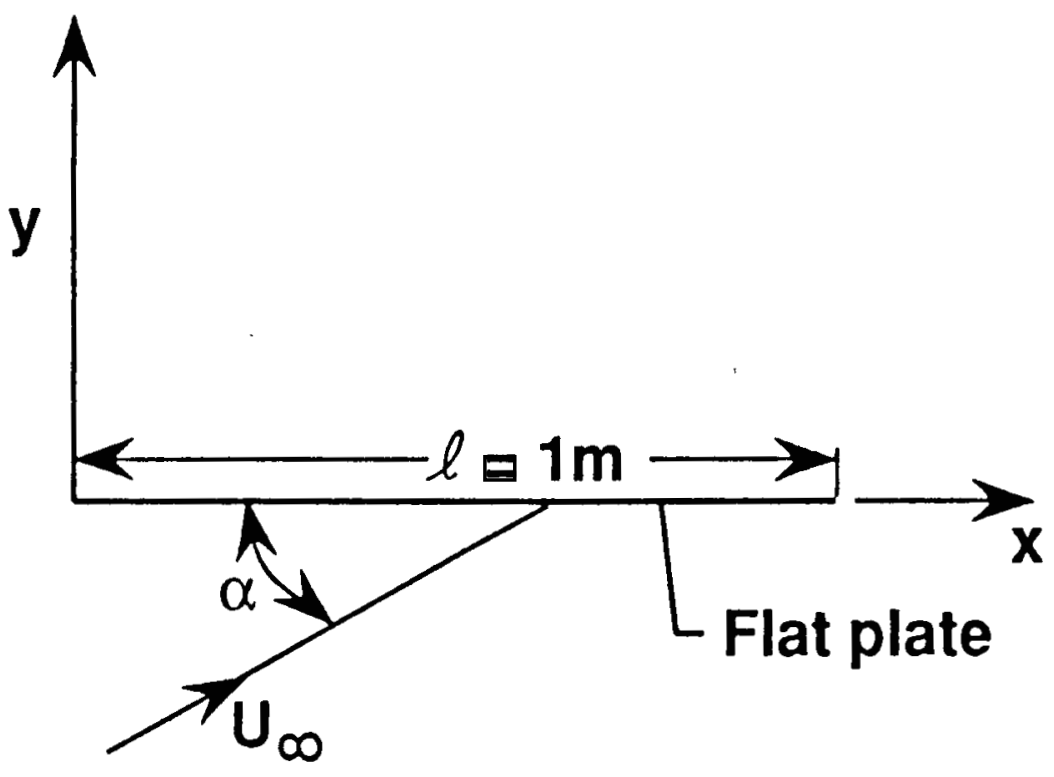

Figure 1. Flat plate configuration at incidence. 


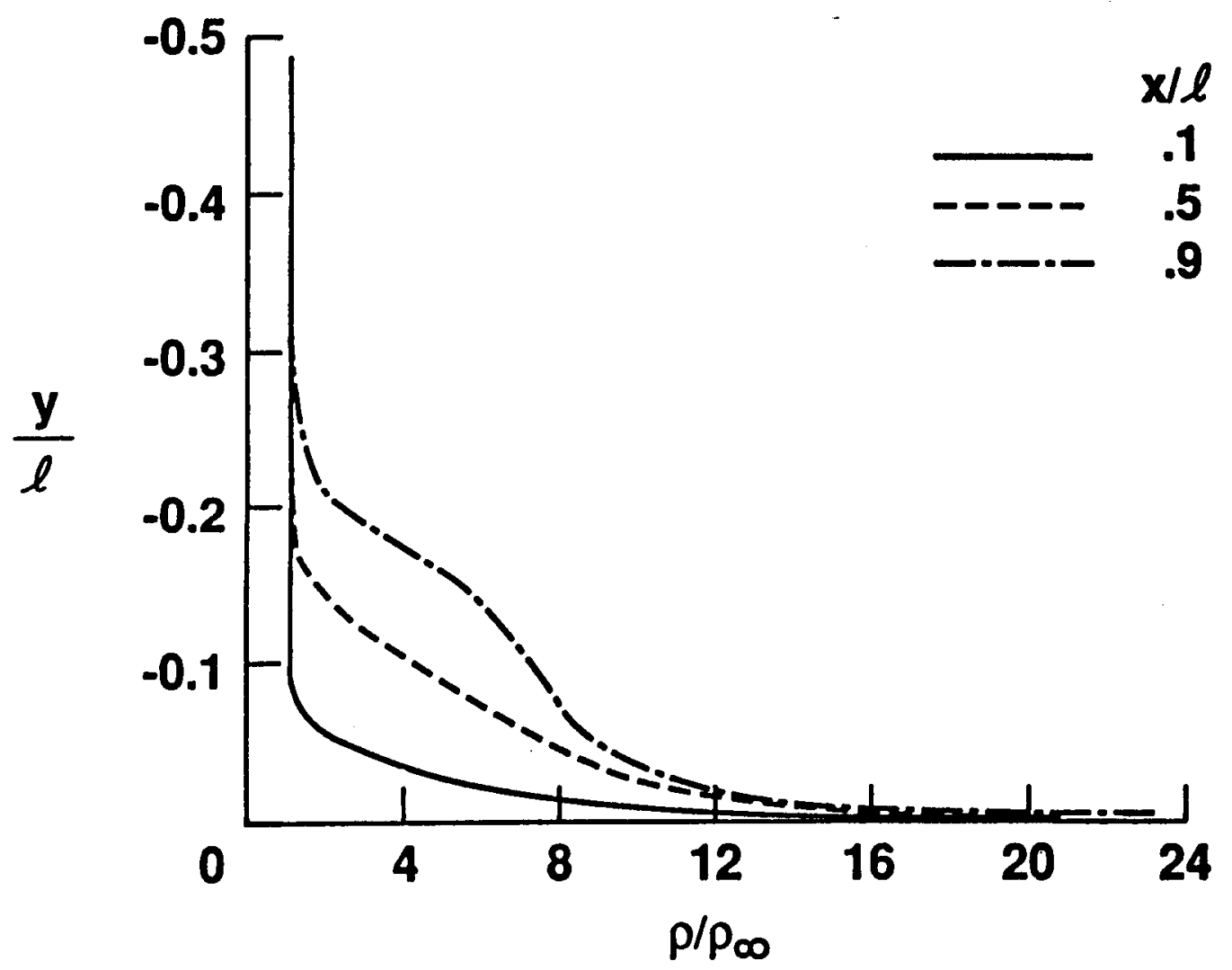

Figure 2. Density profiles normal to the plate surface. $\left(K_{N_{\infty}}=0.023\right.$, and $\alpha=40$ deg. $)$ 


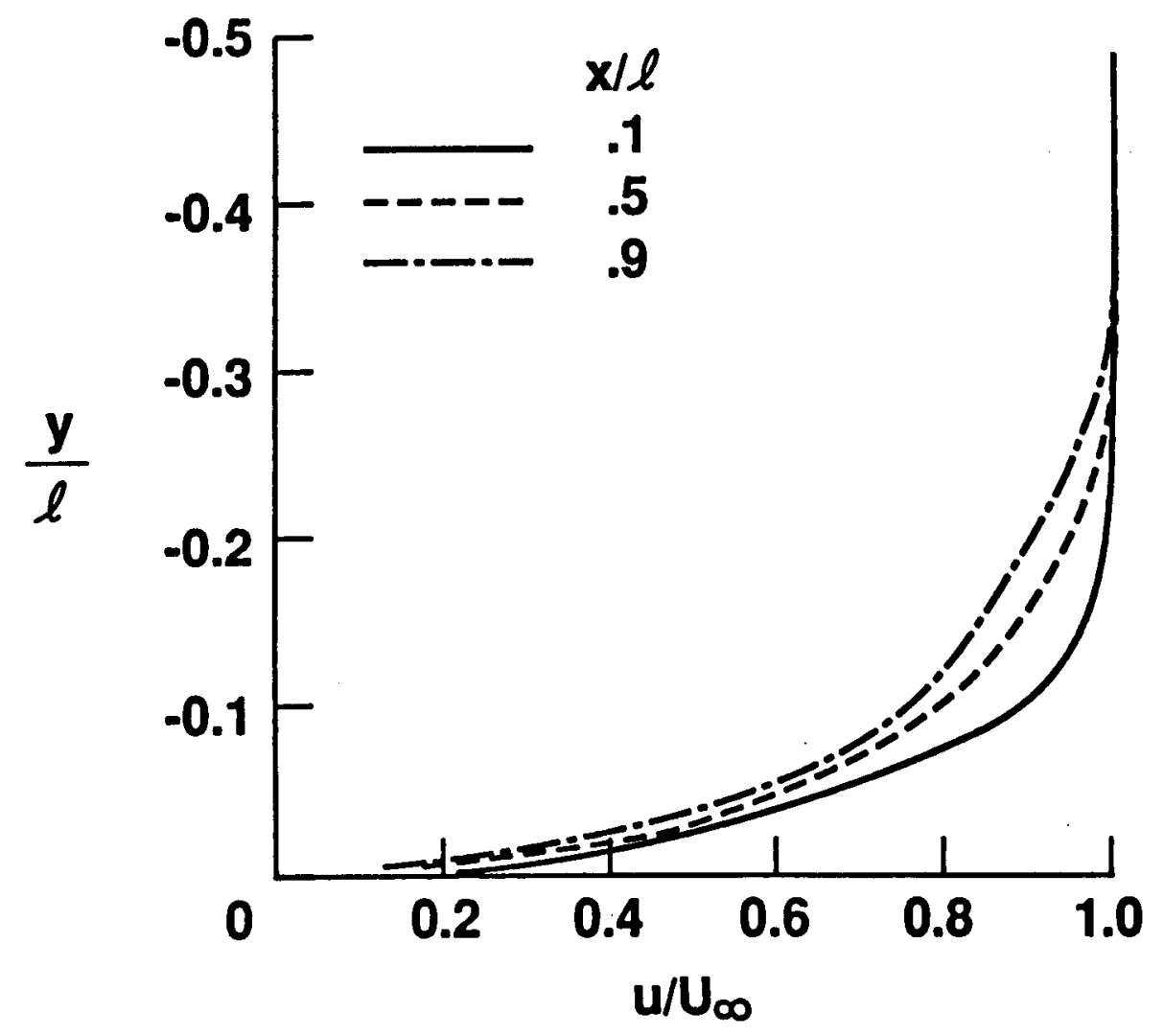

Figure 3. Tangential velocity profiles normal to the plate surface. $\left(K_{N_{\infty}}=0.023\right.$, and $\alpha=40$ deg. $)$ 


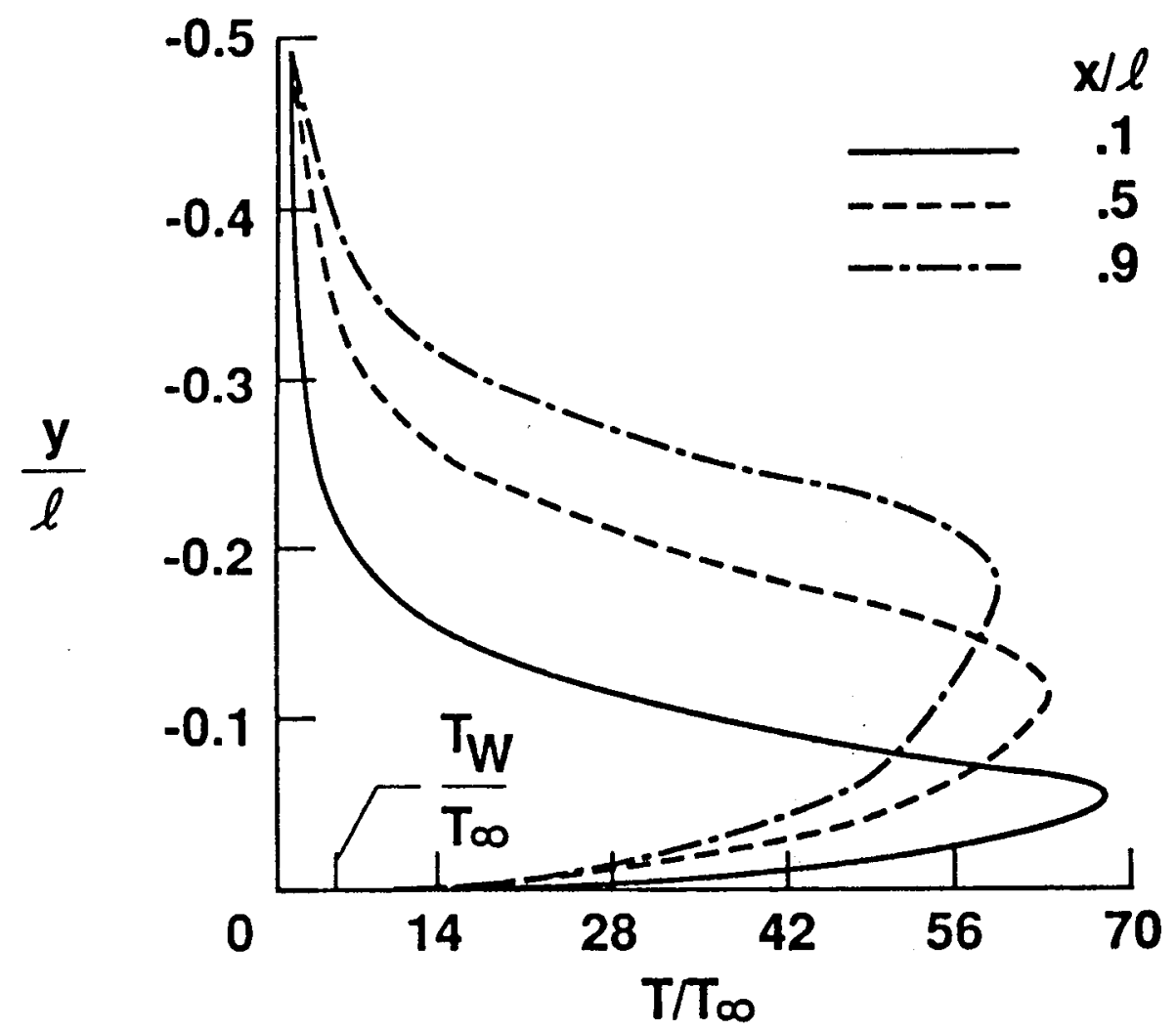

Figure 4. Temperature profiles normal to the plate surface. $\left(K_{N_{\infty}}=0.023\right.$, and $\alpha=40$ deg. $)$ 


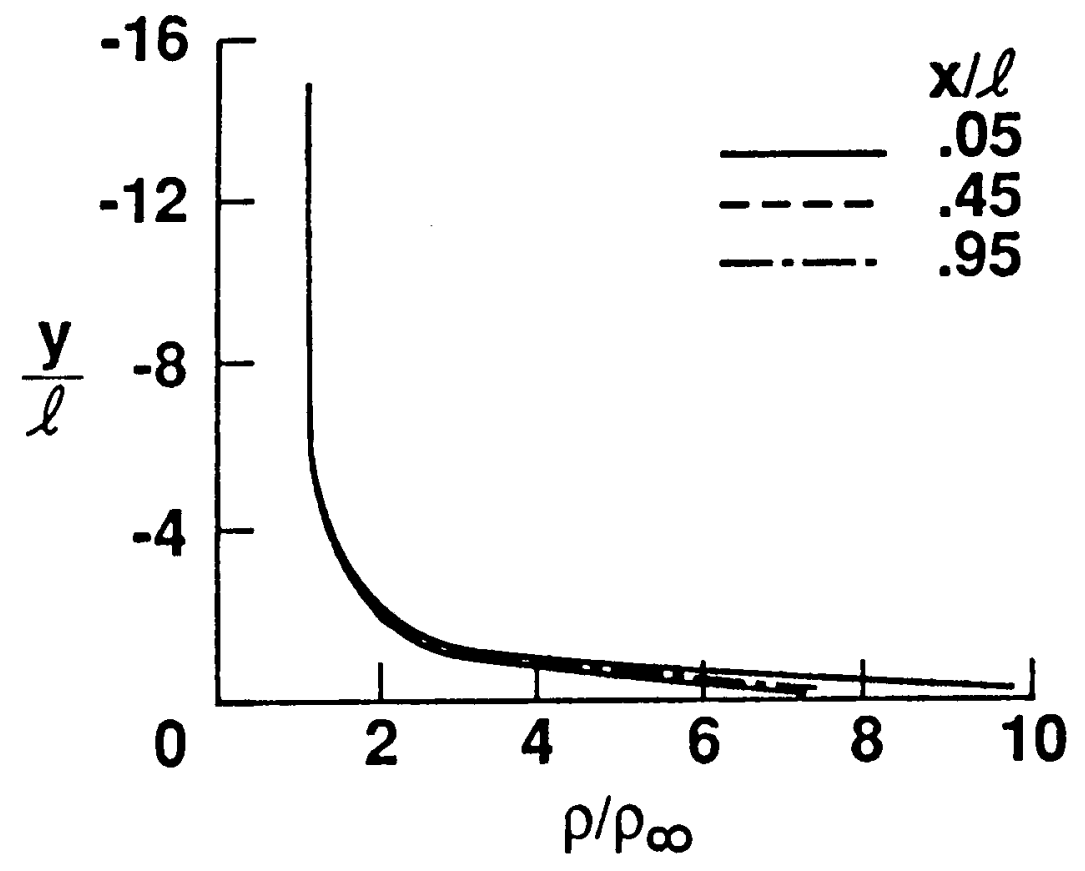

Figure 5. Density profiles normal to the plate surface. $\left(K_{N_{\infty}}=8.439\right.$, and $\alpha=40$ deg. $)$ 


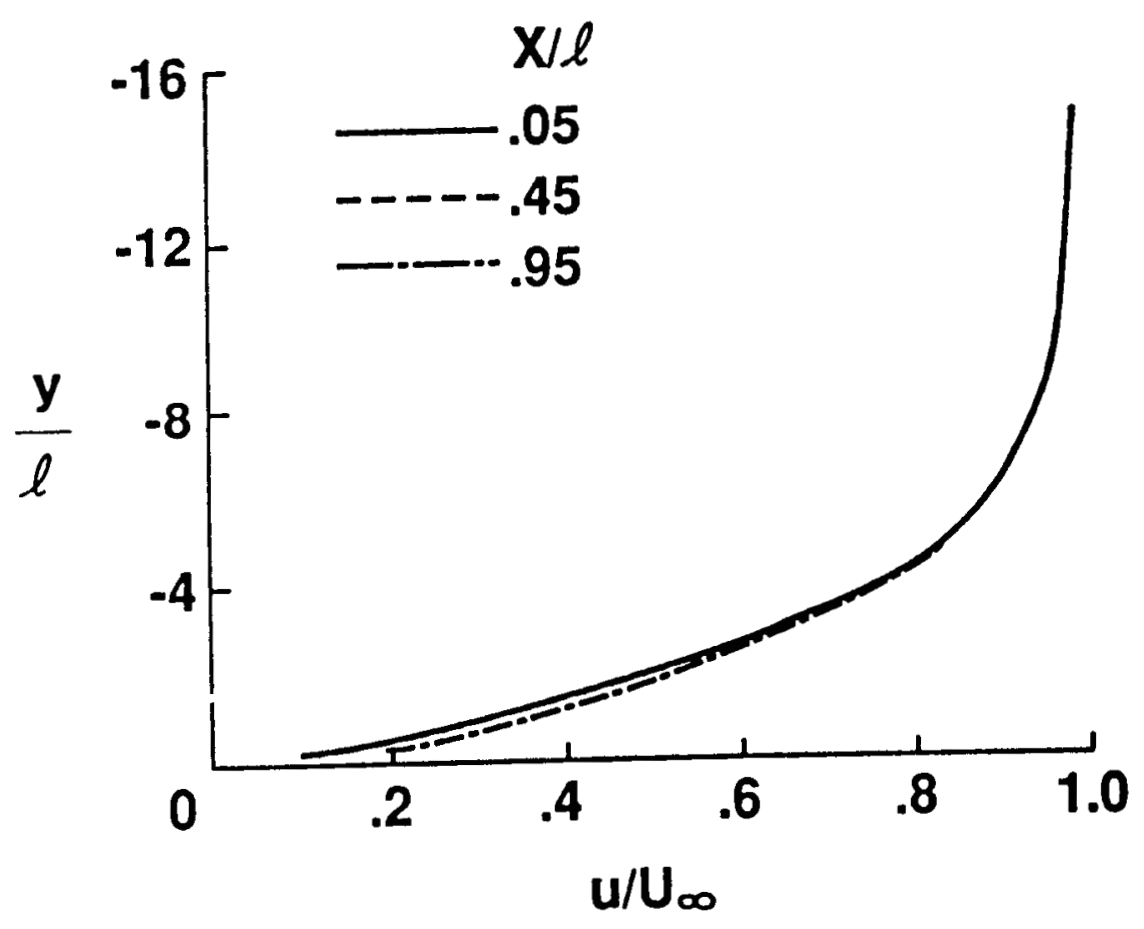

Figure 6. Tangential velocity profiles normal to the plate surface. $\left(K_{N_{\infty}}=8.439\right.$, and $\alpha=40$ deg. $)$ 


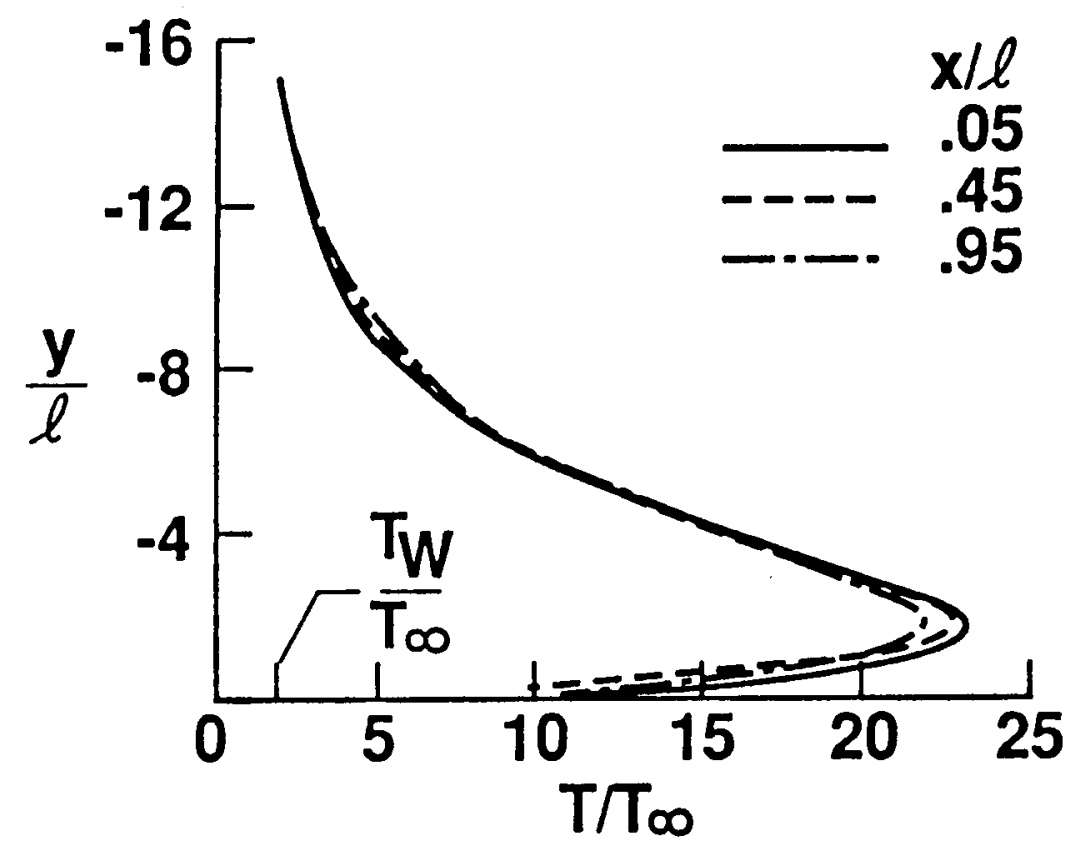

Figure 7. Temperature profiles normal to the plate surface. $\left(K_{N_{\infty}}=8.439\right.$, and $\alpha=40$ deg. $)$ 


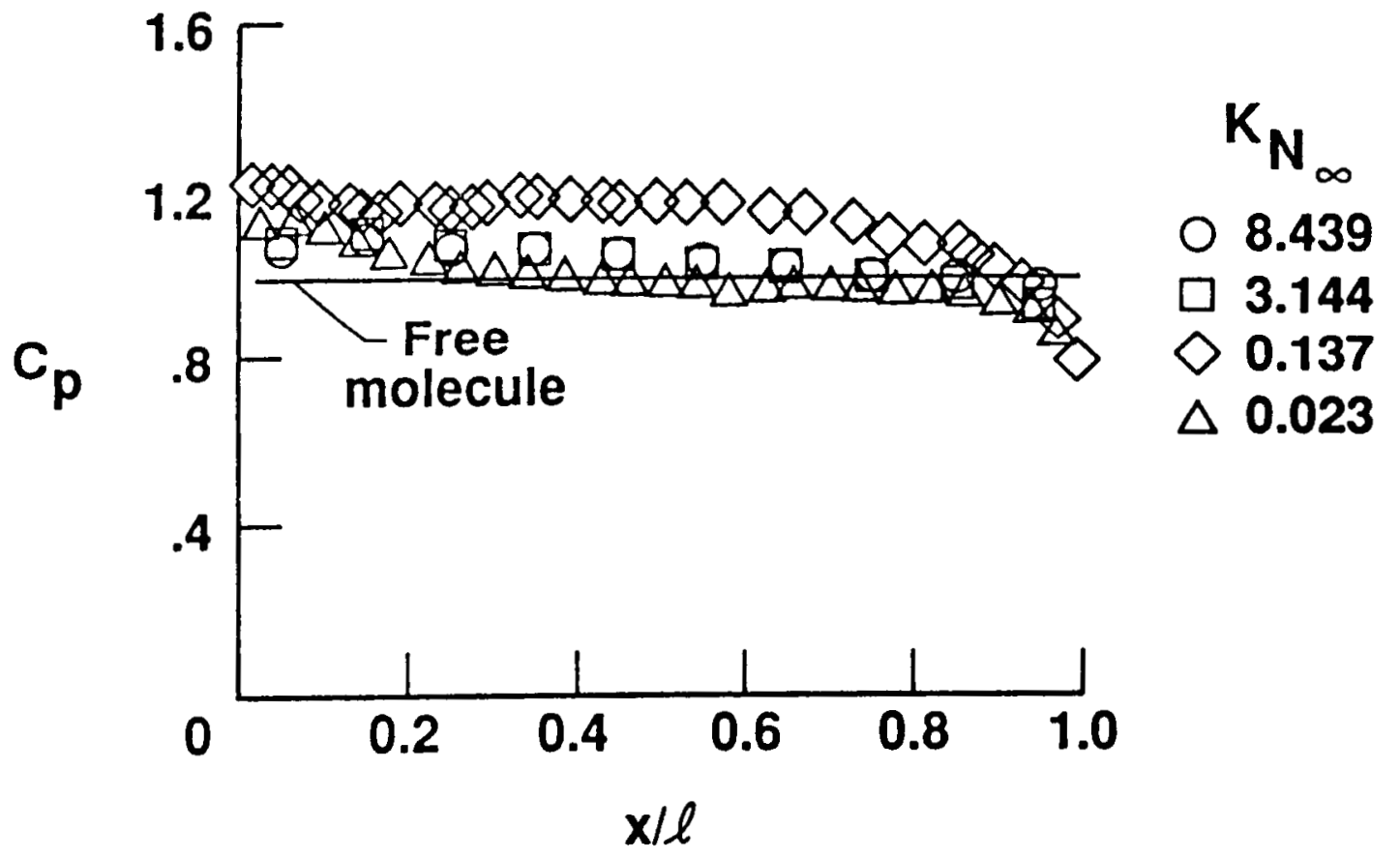

Figure 8. Effect of rarefaction on the compression side surface pressure coefficient.

( $\alpha=40$ deg.) 


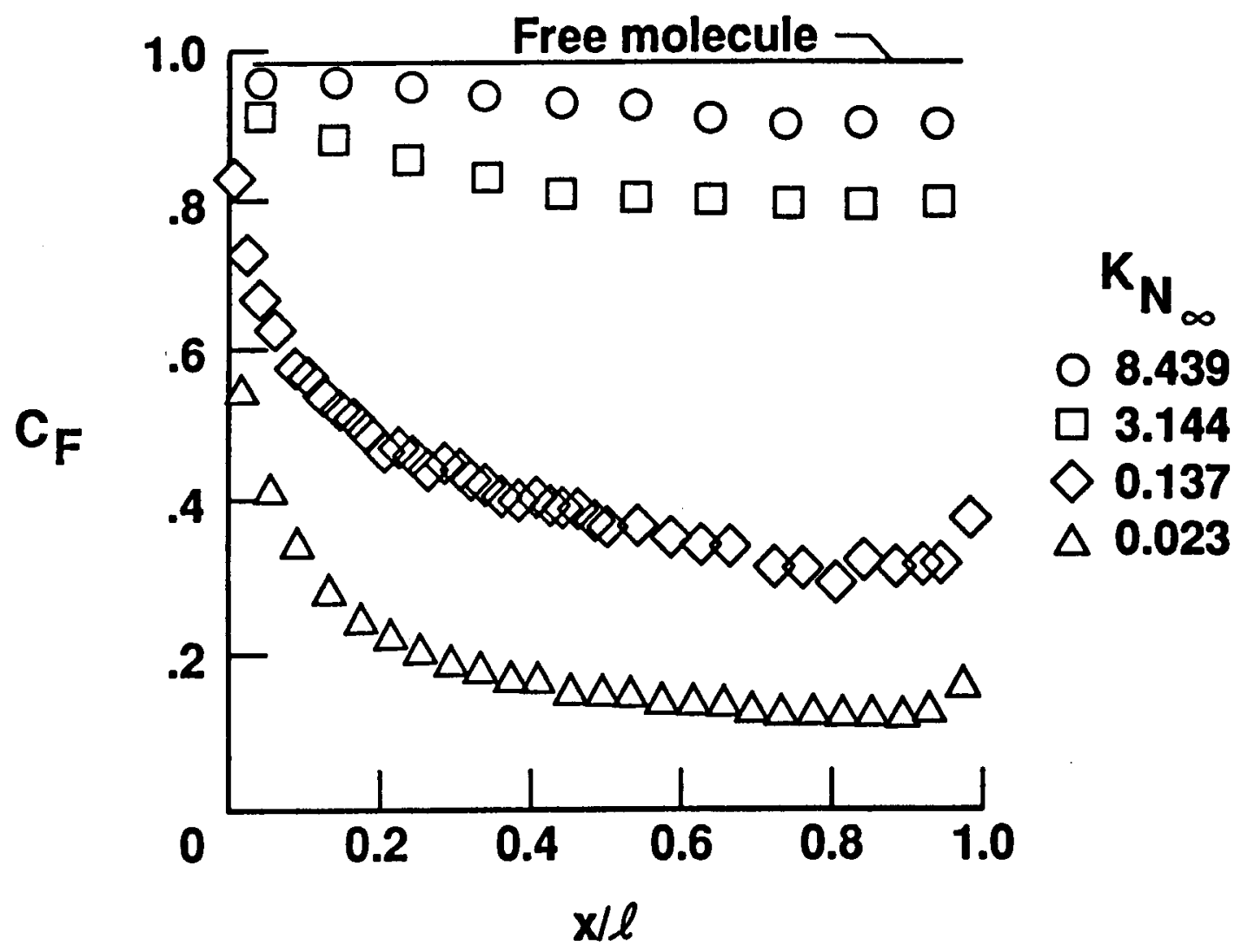

Figure 9. Effect of rarefaction on the compression side surface skin-friction coefficient.

( $\alpha=40$ deg.) 


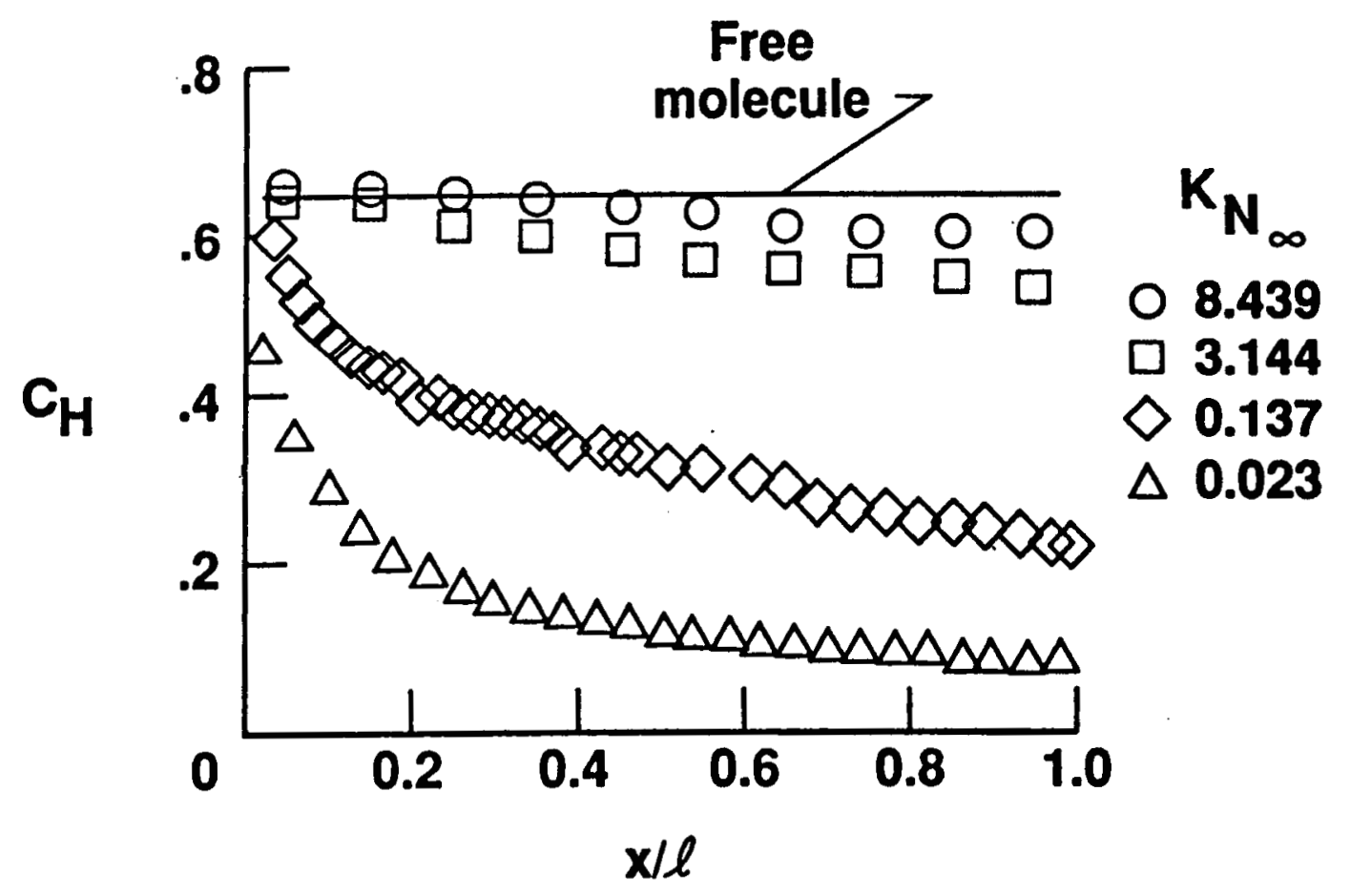

Figure 10. Effect of rarefaction on the compression side surface heat transfer coefficient.

$$
\text { ( } \alpha=40 \text { deg.) }
$$




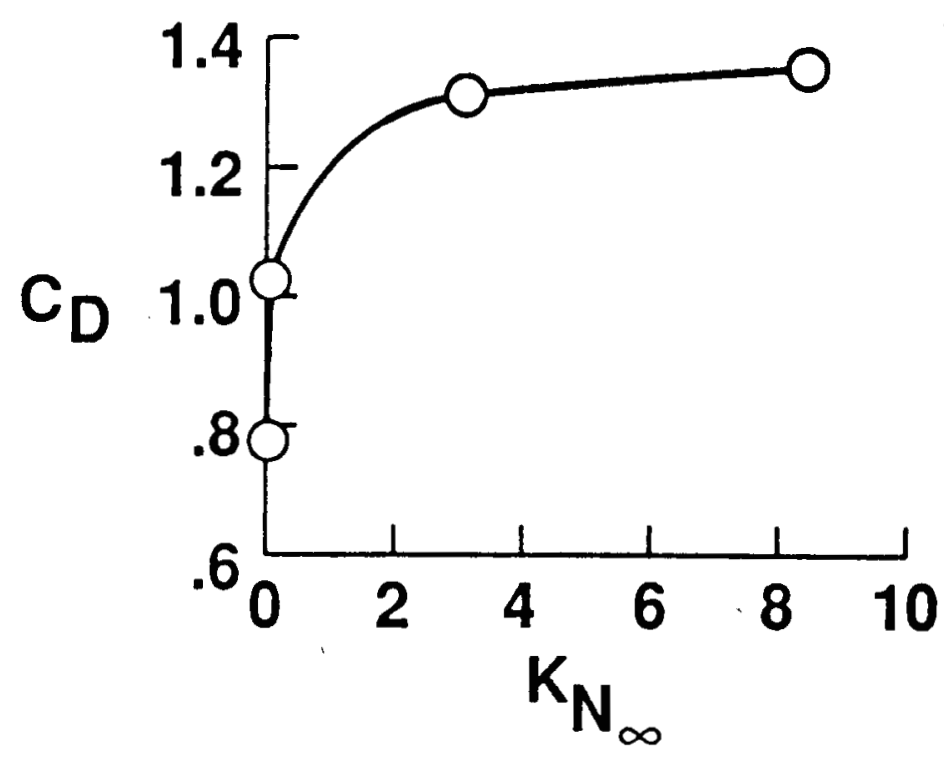

Figure 11. Drag coefficient versus Knudsen number. ( $\alpha=40$ deg.) 


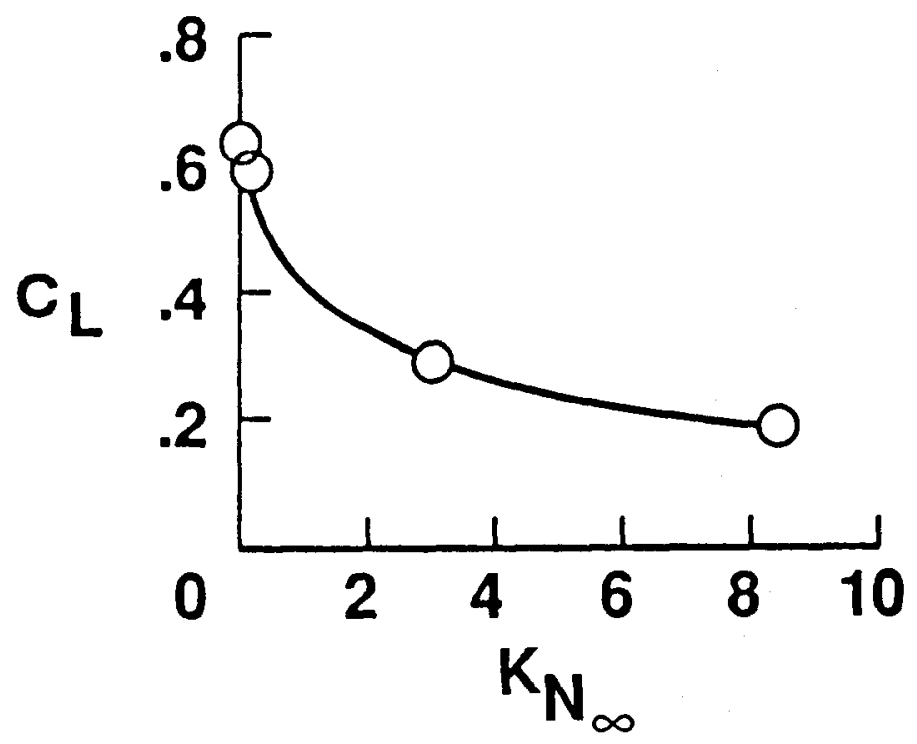

Figure 12. Lift coefficient versus Knudsen number.

( $\alpha=40$ deg.) 


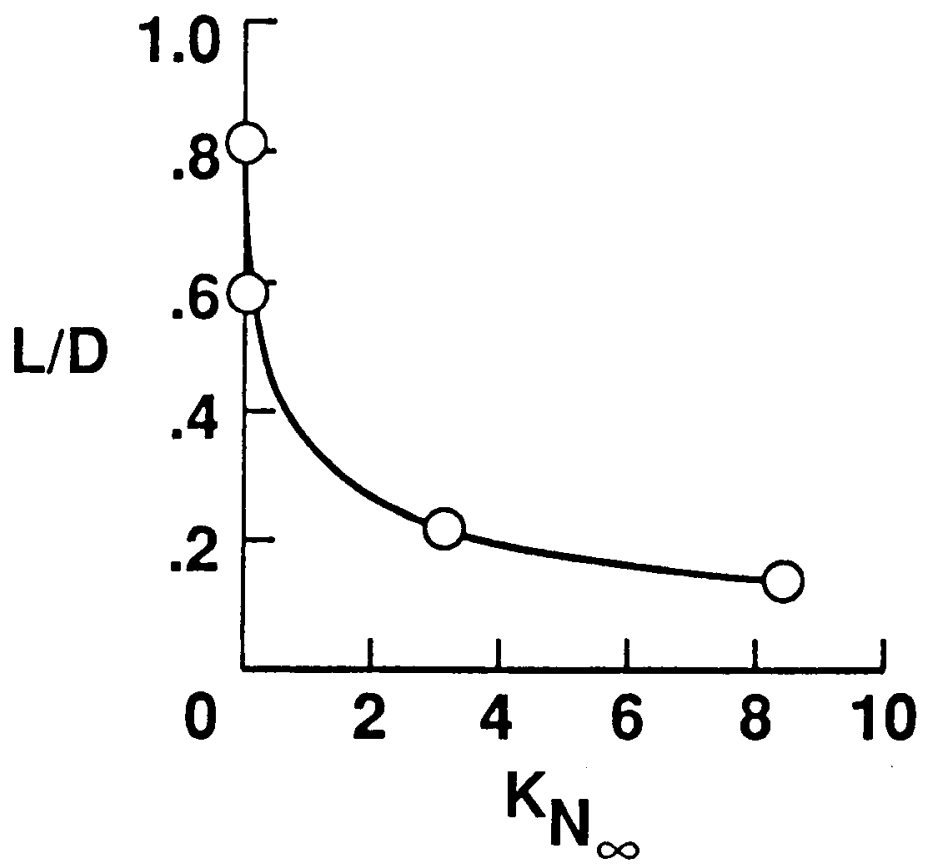

Figure 13. Lift-drag ratio versus Knudsen number. ( $\alpha=40$ deg.) 


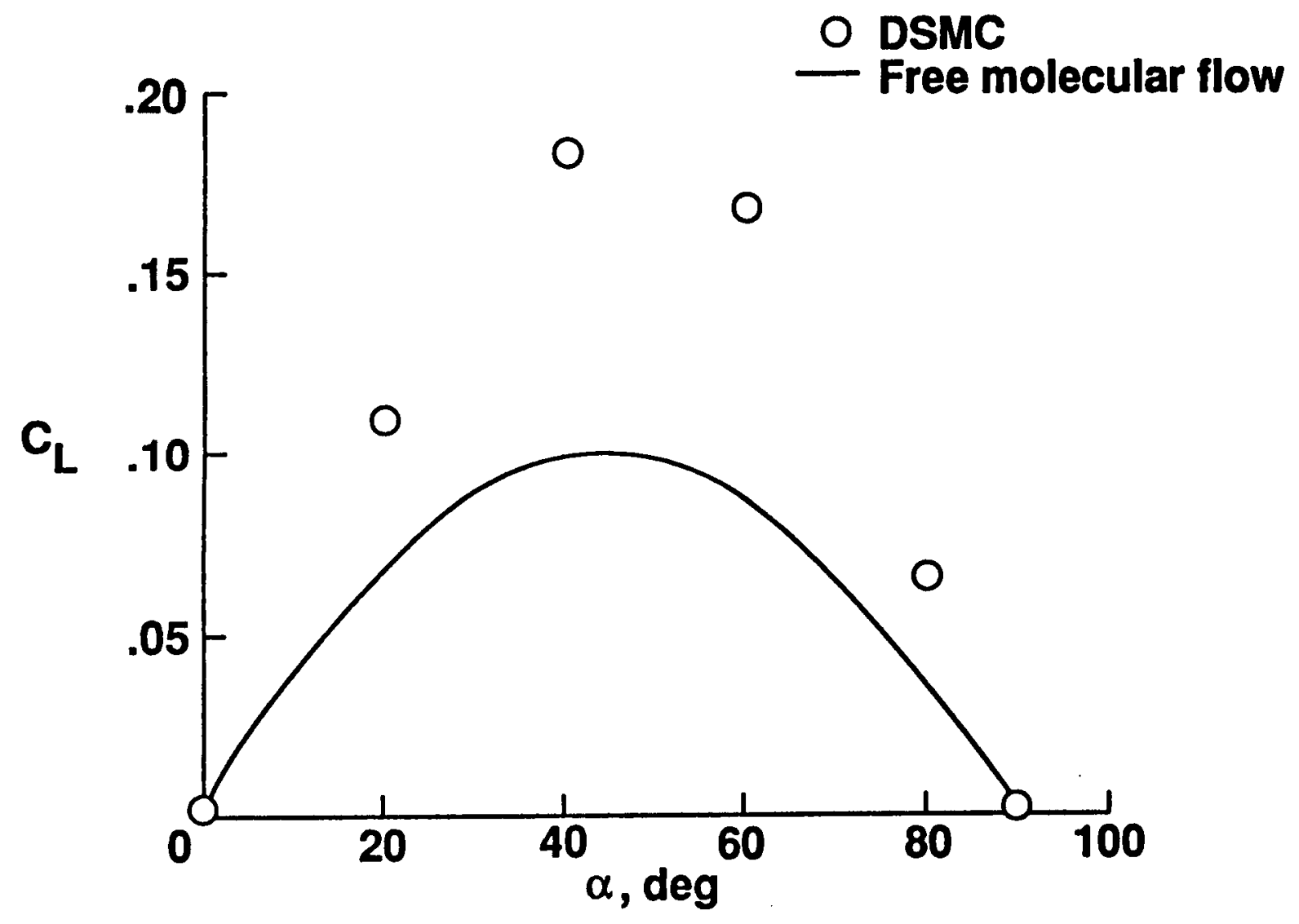

Figure 14. Lift coefficient versus incidence angle for $\mathrm{KN}_{\infty}=8.439$. 


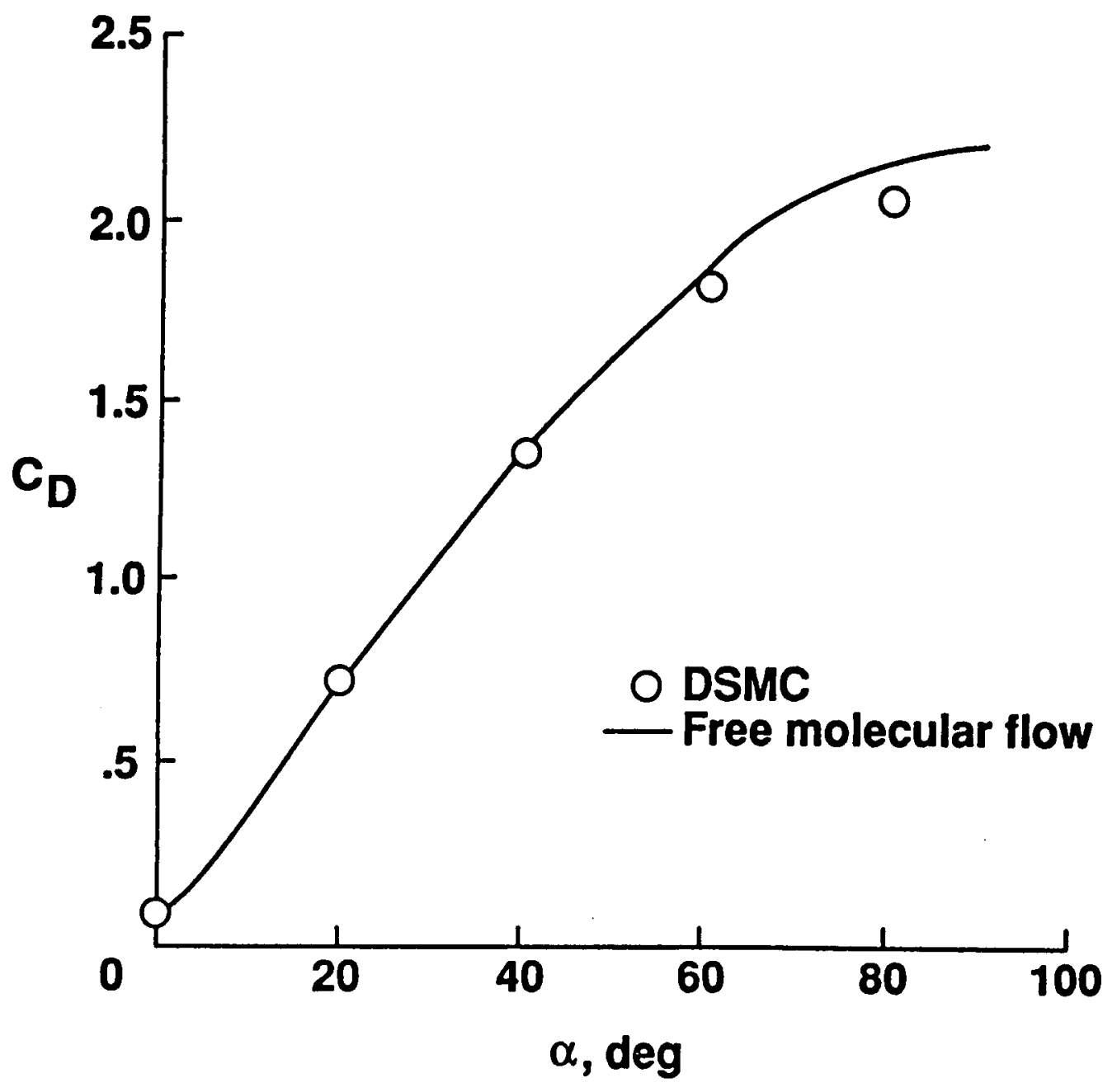

Figure 15. Drag coefficient versus incidence angle for $\mathrm{K}_{N_{\infty}}=8.439$. 


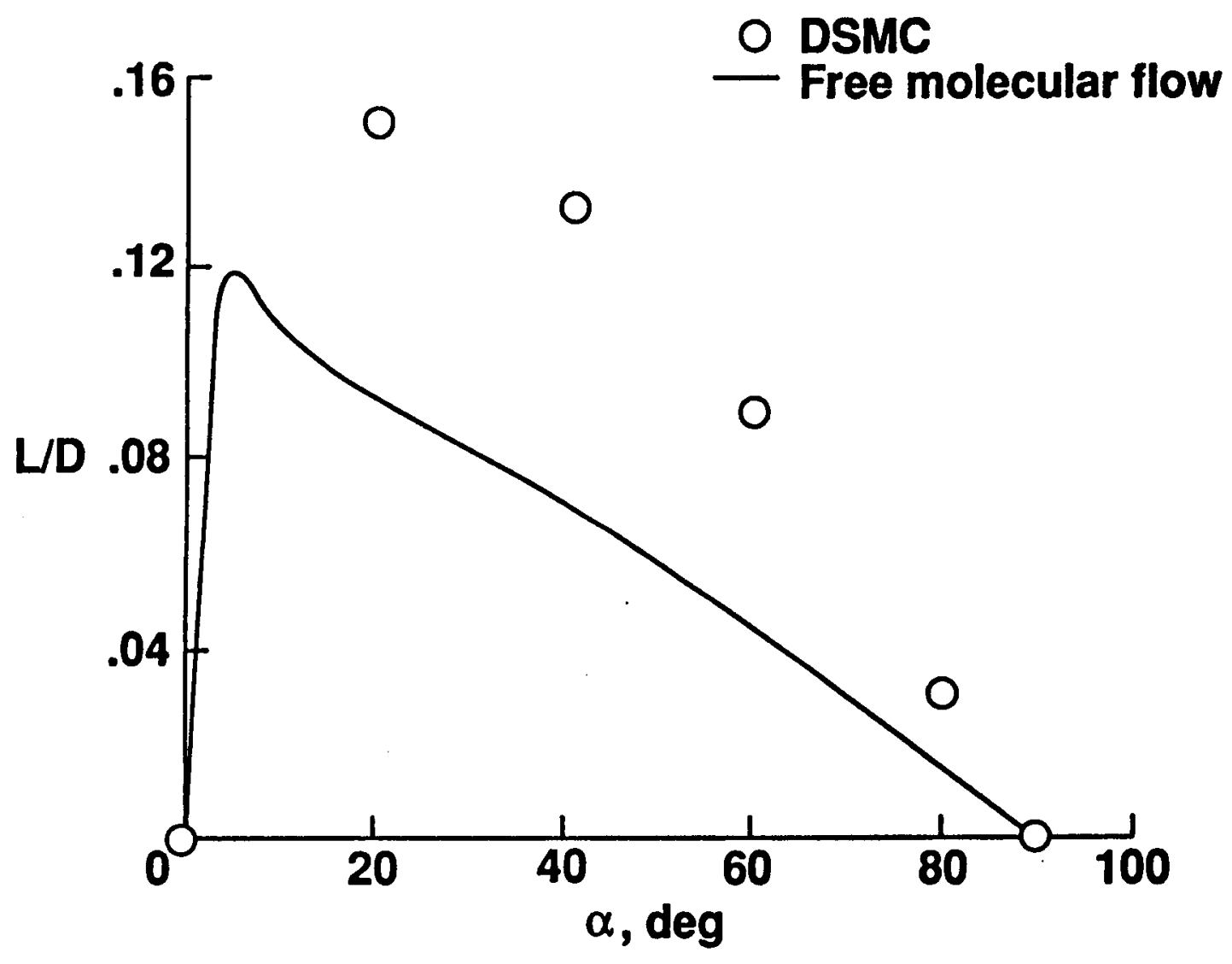

Figure 16. Lift-drag ratio versus incidence angle for $K_{N_{\infty}}=8.439$. 


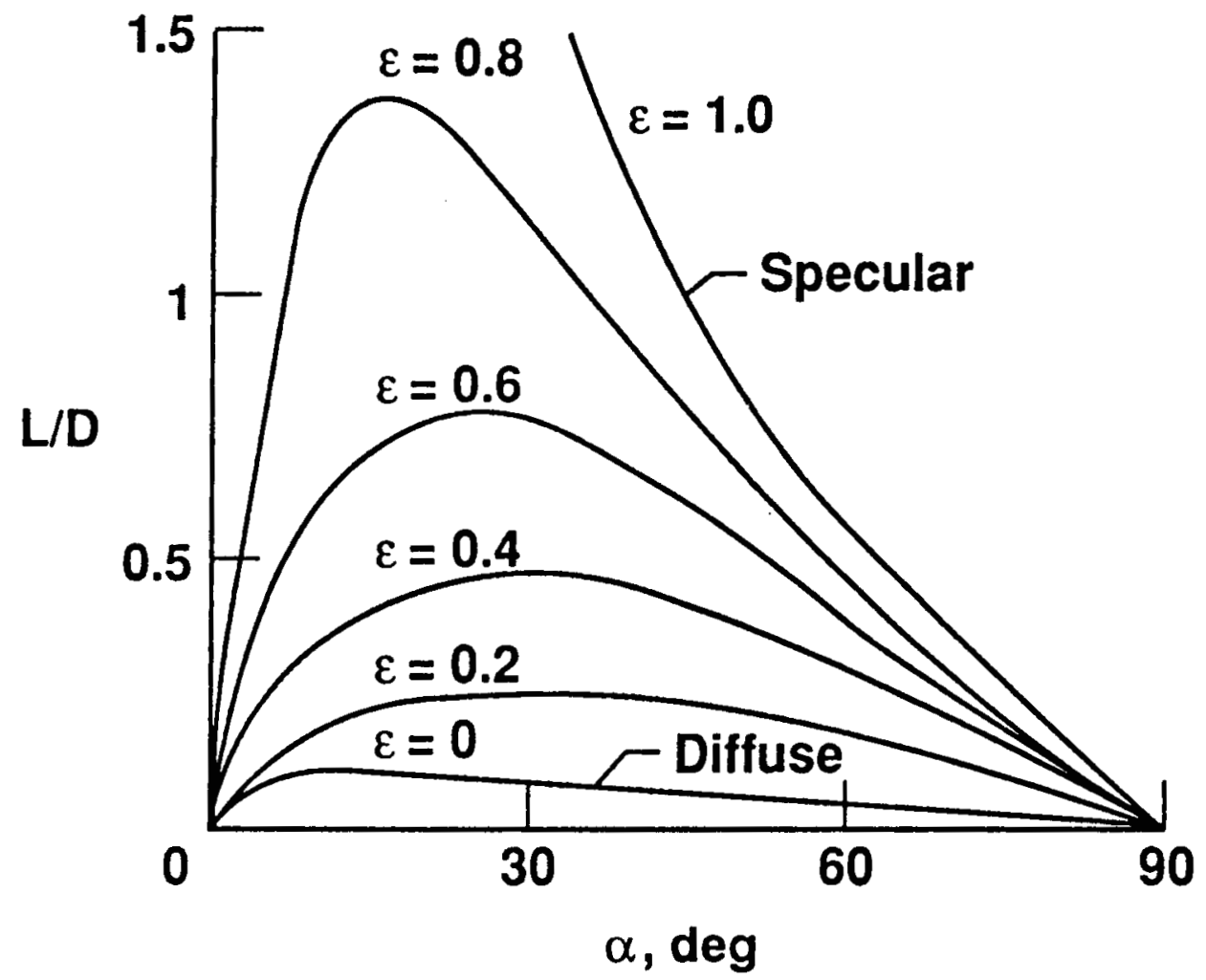

Figure 17. Flat plate free molecule lift-drag ratio versus incidence angle.

$$
\left(S_{\infty}=13.1 \text { and } T w / T_{\infty}=2.0\right)
$$




\begin{tabular}{|c|c|c|c|}
\hline \multicolumn{4}{|c|}{ Report Documentation Page } \\
\hline $\begin{array}{l}\text { 1. Report No. } \\
\text { NASA TM-101493 }\end{array}$ & 2. Government Accession No. & \multicolumn{2}{|c|}{ 3. Recipient's Catalog No. } \\
\hline \multirow{2}{*}{\multicolumn{2}{|c|}{$\begin{array}{l}\text { 4. Title and Subtitle } \\
\text { Rarefied Flow Past a Flat Plate at Incidence }\end{array}$}} & \multicolumn{2}{|c|}{$\begin{array}{l}\text { 5. Report Date } \\
\text { October } 1988\end{array}$} \\
\hline & & \multicolumn{2}{|c|}{ 6. Performing Organization Code } \\
\hline \multirow{2}{*}{\multicolumn{2}{|c|}{$\begin{array}{l}\text { 7. Author(s) } \\
\text { Virendra K. Dogra } \\
\text { James N. Moss } \\
\text { Joseph M. Price }\end{array}$}} & \multicolumn{2}{|c|}{ 8. Performing Organization Report No. } \\
\hline & & \multicolumn{2}{|c|}{$\begin{array}{l}\text { 10. Work Unit No. } \\
506-40-91-03\end{array}$} \\
\hline \multirow{2}{*}{\multicolumn{2}{|c|}{$\begin{array}{l}\text { 9. Performing Organization Name and Address } \\
\text { NASA Langley Research Center } \\
\text { Hampton, VA 23665-5225 }\end{array}$}} & \multicolumn{2}{|c|}{ 11. Contract or Grant No. } \\
\hline & & \multirow{2}{*}{\multicolumn{2}{|c|}{$\begin{array}{l}\text { 13. Type of Report and Period Covered } \\
\text { Technical Memorandum }\end{array}$}} \\
\hline \multirow{2}{*}{\multicolumn{2}{|c|}{$\begin{array}{l}\text { 12. Sponsoring Agency Name and Address } \\
\text { Nationa1 Aeronautics and Space Administration } \\
\text { Washington, DC 20546-0001 }\end{array}$}} & & \\
\hline & & \multicolumn{2}{|c|}{ 14. Sponsoring Agency Code } \\
\hline \multicolumn{4}{|c|}{$\begin{array}{l}\text { 15. Supplementary Notes } \\
\text { Presented at the Sixteenth International Symposium on Rarefied Gas } \\
\text { Dynamics, Pasadena, California, July 10-16, 1988. Submitted for publication } \\
\text { in the proceedings of l6th RGD meeting. } \\
\text { Virendra K. Dogra: Vigyan Research Associates, Inc., Hampton, Virginia. } \\
\text { James N. Moss and Joseph M. Price: Langley Research Center, Hampton, Virginia. }\end{array}$} \\
\hline \multicolumn{4}{|c|}{$\begin{array}{l}\text { 16. Abstract } \\
\text { Results of a numerical study using the direct simulation Monte Carlo (DSMC) } \\
\text { method are presented for the transitional flow about a flat plate at } 40 \text { degree } \\
\text { incidence. The plate has zero thickness and a length of } 1.0 \mathrm{~m} \text {. The flow condi- } \\
\text { tions simulated are those experienced by the Shuttle Orbiter during reentry at } \\
7.5 \mathrm{~km} / \mathrm{s} \text {. The range of freestream conditions are such that the freestream } \\
\text { Knudsen number values are between } 0.02 \text { and } 8.4 \text {, that } 1 \mathrm{~s} \text {, conditions that } \\
\text { encompass most of the transitional flow regime. The DSMC simulations show that } \\
\text { transitional effects are evident when compared with free molecule results for all } \\
\text { cases considered. The calculated results demonstrate clearly the necessity of } \\
\text { having a means of identifying the effects of transitional flow when making } \\
\text { aerodynamic flight measurements as are currently being made with the Space } \\
\text { Shuttle Orbiter vehicles. Previous flight data analyses have relied exclusively } \\
\text { on adjustments in the gas-surface interaction models without accounting for the } \\
\text { transitional effect which can be comparable in magnitude. The present calcula- } \\
\text { tions show that the transitional effect at } 175 \text { km would increase the Space } \\
\text { Shuttle Orbiter } 11 \text { ft-drag ratio by } 90 \text { percent over the free molecular value. }\end{array}$} \\
\hline \multicolumn{4}{|c|}{\begin{tabular}{l|l} 
17. Key Words (Suggested by Author(s)) & 18. Distribution Statement \\
Transitional flow effects & Unclassified - Unlimited \\
Aerodynamic characteristics & Subject Category 34 \\
Direct simulation Monte Carlo &
\end{tabular}} \\
\hline $\begin{array}{l}\text { 19. Security Classif. lof this report) } \\
\text { Unclassified }\end{array}$ & $\begin{array}{l}\text { 20. Security Classif. (of this page) } \\
\text { Unclassi fied }\end{array}$ & $\begin{array}{l}\text { 21. No. of pages } \\
30\end{array}$ & $\begin{array}{r}\text { 22. Price } \\
\text { A0 } 3\end{array}$ \\
\hline
\end{tabular}

